Am. J. Trop. Med. Hyg., 62(4), 2000, pp. 496-501

Copyright $(\mathcal{C} 2000$ by The American Society of Tropical Medicine and Hygiene

\title{
ECONOMIC HARDSHIP AND SEXUALLY TRANSMITTED DISEASES IN HAITI'S RURAL ARTIBONITE VALLEY
}

\author{
DANIEL W. FITZGERALD, FRIEDA BEHETS, ANGELA CALIENDO, DOMINIQUE ROBERFROID, CATHERINE LUCET, \\ JENNIFER W. FITZGERALD, AND LUC KUYKENS \\ Hospital Albert Schweitzer, Deschapelles, Haiti; Division of International Medicine and Infectious Diseases, Cornell University \\ Medical College, New York, New York; Department of Medicine, University of North Carolina at Chapel Hill, North Carolina; \\ Massachusetts General Hospital, Boston, Massachusetts
}

\begin{abstract}
A study was conducted to determine the prevalence rate and risk factors for sexually transmitted diseases (STDs) in Haiti's rural Artibonite Valley. Women attending antenatal services at Hospital Albert Schweitzer from October to December 1996 were tested for gonorrhea, chlamydia, trichomonas, syphilis, and human immunodeficiency virus (HIV). Of the 476 women tested, 121 (25.4\%) had trichomonas, 11/475 (2.3\%) had gonorrhea, 51/475 (10.7\%) had chlamydia, 32/474 (6.8\%) were seropositive for syphilis, 20/469 (4.3\%) were seropositive for HIV, and 191 $(40.1 \%)$ had at least one STD. Nearly $30 \%$ of the women reported having entered a sexual relationship out of economic necessity and had increased odds of HIV infection, Odds Ratio $(\mathrm{OR}) 6.3(P<0.001)$. We postulate that due to recent economic hardship in rural Haiti, women are entering into sexual relationships out of economic necessity and that this trend is contributing to the growing HIV epidemic. We recommend STD prevention and development programs that target young people and economically disadvantaged women.
\end{abstract}

\section{INTRODUCTION}

In most developing countries, the prevalence rate of sexually transmitted diseases (STDs) is substantially higher in urban areas and consequently, STD prevention efforts focus there. ${ }^{1,2}$ In Haiti, several recent reports cast doubt upon the wisdom of ignoring rural populations. A report on the human immunodeficiency virus (HIV) in Haiti documented rapidly rising rates of HIV infection among rural women with children. ${ }^{3}$ In another report, congenital syphilis rates in rural Haiti, 550 per 100,000 live births, were among the highest in the world. ${ }^{4}$

Over the last few years, rural Haiti has suffered tremendous economic hardship. ${ }^{5}$ The combination of drought, land erosion, and overpopulation has contributed to chronic malnutrition so that weight-for-age in thirty-five percent of children under the age 5 years is low. ${ }^{6,7}$ A 1991 military coup and the ensuing international economic embargo contributed to economic difficulties and to a deterioration in the already marginal health status of the rural poor. ${ }^{89}$ Anthropologic studies suggest that the economic hardship in rural Haiti has led to new patterns of sexual relationships and that some of these patterns may be related to increased transmission of sexually transmitted diseases. ${ }^{10,11}$ Prompted by these reports and hypothesizing that recent economic hardship in rural Haiti has created fertile ground for the spread of HIV and other STDs, a study to determine the prevalence rates and risk factors for HIV and STDs was conducted at Hospital Albert Schweitzer (HAS) in Haiti's rural Artibonite Valley.

\section{MATERIALS AND METHODS}

Patient recruitment and specimen collection. We conducted a cross-sectional sentinel prevalence study from October to December 1996. Hospital Albert Schweitzer serves the population of Haiti's Artibonite Valley with village health workers, community dispensaries, and a central hospital. The Artibonite Valley is divided into 8 rural zones, with each zone served by a community dispensary. For over 20 years, HAS has conducted health surveillance for the Ar- tibonite Valley. ${ }^{12}$ Based on 1995 surveillance data, the population of the zones served by HAS was estimated at 200,000 people with 7,500 pregnancies annually. More than $80 \%$ of pregnant women seek antenatal care at the HAS community dispensaries. We chose to sample women at two community dispensaries in the rural zones of Deschapelles and Liancourt. The choice was pragmatic. These two dispensaries are within a day's walk of Hospital Albert Schweitzer. Even if the roads were impassable, as is often the case, specimens could be hand carried to the central HAS laboratory for processing and storage. Based upon HAS surveillance data and government census data, ${ }^{13}$ the zones of Deschapelles and Liancourt are comparable to the other valley zones with regards to population demographics and socioeconomic characteristics. Previous sero-prevalence studies $^{4}$ suggest that the prevalence rates of syphilis and HIV in all 8 valley zones are similar (Pape $J$, unpublished data). The HAS Research Ethics Committee approved the study design and consent process. Informed consent was obtained orally from all participants prior to enrollment.

All pregnant women attending their initial prenatal consultation at the community dispensaries of Deschapelles and Liancourt were eligible for inclusion in this study. After obtaining consent, a local health worker interviewed women in Haitian Creole using a structured study questionnaire that had been focus-group evaluated and validated by field-testing. They were asked to provide information about basic demographics, exposure to STD risk factors, and related symptoms. Their blood was collected, the serum separated immediately, and an aliquot removed for research purposes. Serum was tested for syphilis on-site by the Rapid Plasma Reagin (RPR) (Becton Dickinson, Sparks, MD). Quality control for on-site RPR testing is routinely done by retesting a representative sample of specimens at the central hospital lab. Participants also provided a first-flow urine specimen which was tested for white blood cells (LED) using a leukocyte esterase dipstick (Multistix, Miles, Inc., Kankakee, IL). All samples that were trace reactive and above were considered positive. A sample of urine was saved. Vaginal swabbing provided secretions that were examined by $400 \times$ 
direct microscopy for Trichomonas vaginalis. Results of the RPR, the LED, and microscopy were recorded on the patient's study questionnaire.

Treatment regimens following the Haitian national guidelines for the treatment of sexually transmitted diseases ${ }^{14,15}$ were instituted that same day if needed based upon individual clinical and laboratory data. Women with a positive RPR received intramuscular penicillin and were given follow-appointments to complete three doses. All women with a positive LED, with trichomonas on microscopy, or who reported vaginal discharge were treated syndromically for vaginal discharge. All women reporting vaginal ulcers were treated syndromically for genital ulcer disease. Women with bacterial vaginosis or Candida vaginitis by microscopy also received treatment (data not shown).

Laboratory testing. Urine and serum samples were transported on ice from the dispensaries to a central laboratory at Hospital Albert Schweitzer. A unique four-digit study number was assigned to identify each enrollee's questionnaire, urine sample, and blood sample; the name was removed and no records linking the study number and name were kept. All positive RPR samples were confirmed by fluorescent treponemal antibody testing (FTA-Abs) (Becton Dickinson, Sparks, MD) at the Institut National de Laboratoire et de Recherche in Port au Prince, Haiti. Serum HIV antibodies were detected by enzyme-linked immunosorbent assay (ELISA) (Abbott Diagnostics, Abbott Park, IL). Positive samples were confirmed by a second ELISA (Sanofi Diagnostics Pasteur, Chaska, MN) at the Institut National de Laboratoire et de Recherche.

Urine samples were frozen at $-20^{\circ} \mathrm{C}$ and transported on wet ice to Massachusetts General Hospital, Boston, Massachusetts where they were tested by Amplicor polymerase chain reaction (PCR) for Neisseria gonorrhoeae and Chlamydia trachomatis (Roche Diagnostics, Branchburg, NJ). At the time of this study, Amplicor PCR of urine was not approved for clinical testing.

Data analysis. Questionnaire and laboratory data were entered into EPI INFO 6 (Centers for Disease Control and Prevention, Atlanta, GA) and analyzed using SAS (SAS Institute, Cary, NC). To determine a difference in two proportions, chi-square with Yates correction was used. For expected cell values of less than five, Fisher's exact test was used. Means and medians were compared by Student's t-test and the Wilcoxon rank sum test respectively. The mortality of children previously born to each woman was determined by dividing the number of children reported to have died by the number of previous live births. Multivariate analysis was done using a backward logistic regression procedure. Variables related to the outcome by univariate analysis or by previous clinical reports were included in the original model. Variables were removed from the model if $\alpha$ was greater than 0.05. All variables found to be confounders causing a10\% change in another predictor were left in the model. Effect modifiers were evaluated, but in the models presented in this report, none were found.

We report risk factors for disease and possible manifestations of disease as risk markers. Both risk factors and risk markers are analyzed together in the multivariate model; associations are reported with odds ratios (OR).
RESULTS

Patient characteristics. During the study period, 507 pregnant women presented at the study dispensaries for a first prenatal visit, and 476 (94\%) were enrolled. Characteristics of the enrolles are shown in Table 1 . Of the 476 women, $244(51.3 \%)$ reported being plase or in plasaj Meaning "placed with" plasaj refers to a long-term sexual relationship not formalized by a religious or civil ceremony, often resulting in children and commonly not monogamous. Of the 476 women, 141 (30\%) reported having entered a sexual relationship out of economic necessity. Of these, $100(71 \%)$ were plase compared with $143 / 355(40.0 \%)$ of the women who did not report an economically driven sexual relationship $(P<0.001)$. Of the economically motivated women, $135 / 141(95.7 \%)$ had children with more than one father compared with $45 / 355(12.7 \%)$ of the others $(P<0.001)$.

When asked by the interviewer, $147 / 476$ women studied (30.9\%) reported dysuria; $255(53.7 \%)$ vaginal discharge; $190(40.3 \%)$ vaginal pruritis; $45(9.5 \%)$ vaginal ulcers, and $312(65.8 \%)$ reported having had at least one urogenital symptom in the last year.

Prevalence rates of sexually transmitted diseases, risk factors, and risk markers. The prevalence rates are presented in Table 2. Risk factors for trichomonas infection, the most common STD, included living in a separate house from the father of the unborn child [OR $2.7(P<0.001)]$ and reporting that the father may have another girlfriend [OR 1.6 $(P=0.035)]$. Risk markers for trichomonas were vaginal discharge [OR $1.7(P=0.025)$ ], and vaginal pruritis [OR $2.1(P=0.001)]$. A urine leukocyte esterase test was positive in $97(80 \%)$ of 121 women with trichomonas versus 136 $(38 \%)$ in women without trichomonas [OR $6.5(P<0.001)]$.

Of the 475 women tested, 57 (12\%) had a cervical infection with gonorrhea and/or chlamydia. Risk factors for cervical infection by univariate analysis were 1) age less than 21 years [OR $3.0(P<0.001)], 2)$ onset of sexual activity before age 18 [OR $2.0(P=0.028)], 3)$ living in separately from the father of the child [OR $1.8(P=0.041)]$, 4) reporting that the father may have other sexual partners [OR $1.8(P=0.040)]$, and 5) the father's occupation is truck driver [OR $5.7(P<0.001)]$. Symptoms elicited during medical history were not predictive of cervical infection. Cervical infection was associated with a positive LED [OR 4.1 $(P<0.001)]$ and a positive test for trichomonas [OR $2.4(P$ $=0.003)]$. A positive LED predicted cervical infection with a sensitivity of $77 \%$, and a specificity of $55 \%$. Risk factors and markers for cervical infection with gonorrhea and/or chlamydia by multivariate analysis are presented in Table 3 .

Of the 474 patients tested, $33(7.0 \%)$ had a reactive RPR test and 32/33 (97\%) were confirmed by FTA-Abs. Women with confirmed positive syphilis serology reported a child mortality of $15 \%$, compared with a child mortality of $5 \%$ reported by women without syphilis $(P<0.001)$. Risk factors for positive syphilis serology by univariate analysis were being plase [OR $4.5(P<0.001)$ ], having pregnancies by multiple fathers [OR 3.4, $(P=0.002)$ ], and reporting a sexual relationship out of economic necessity [OR $2.9(P=$ 0.005)] (Table 4).

Risk factors for a positive HIV test by univariate analysis were being plase [OR $4.0(P<0.016)]$, having pregnancies 
TABLE 1

Characteristics of 476 women attending antenatal-care clinics in Haiti's Artibonite Valley

\begin{tabular}{|c|c|c|}
\hline Characteristic & $\begin{array}{c}\text { Number } \\
(\mathrm{N}=476)\end{array}$ & $\%$ \\
\hline Median age $(y r)$ & 25 & - \\
\hline Median age at onset of sexual activity & 18 & - \\
\hline Primagravidas & 138 & 29 \\
\hline Multigravidas & 338 & 71 \\
\hline Ever had child die & 74 & 16 \\
\hline Ever had spontaneous abortion & 55 & 12 \\
\hline Has been pregnant with more than one man & 180 & 38 \\
\hline \multicolumn{3}{|l|}{ Occupation } \\
\hline agriculture and petty trade & 309 & 65 \\
\hline other & 34 & 7 \\
\hline unemployed & 133 & 28 \\
\hline Reports travel out of rural area at least once per month & 35 & 7 \\
\hline Has entered a sexual relationship out of economic necessity & 141 & 30 \\
\hline \multicolumn{3}{|l|}{ Marital status } \\
\hline married & 90 & 19 \\
\hline plasaj* & 244 & 51 \\
\hline friends or lovers & 69 & 15 \\
\hline separated & 73 & 15 \\
\hline Not living in the same household as father of child & 174 & 37 \\
\hline \multicolumn{3}{|l|}{ Father has another sexual partner } \\
\hline yes & 152 & 32 \\
\hline no & 273 & 57 \\
\hline maybe & 51 & 11 \\
\hline \multicolumn{3}{|l|}{ Occupation of father } \\
\hline agriculture & 273 & 57 \\
\hline skilled labor & 63 & 13 \\
\hline merchant & 18 & 4 \\
\hline truck driver & 17 & 4 \\
\hline other & 84 & 17 \\
\hline unemployed & 21 & 5 \\
\hline
\end{tabular}

* Plasaj is a long-term sexual relationship, commonly not monogamous and not formalized by religious or civil ceremony.

by multiple fathers [OR $4.0(P=0.006)]$, reporting a sexual relationship out of economic necessity [OR $4.8(P=0.001)]$, and reporting that the father of child is a merchant [OR 7.7 $(P=0.001)$ ] (Table 5). HIV infection was not associated with travel the outside of the district by either parent.

\section{DISCUSSION}

This study sought to evaluate the prevalence rate of STDs in women attending routine antenatal care in the rural Artibonite Valley of Haiti, and thereby to approximate the prevalence rate of sexually transmitted diseases in the general adult population. Several reports from other developing countries comparing STD prevalence rates in sentinel groups and the general adult population have validated this approach. ${ }^{16-18}$

The STD prevalence rate found in the rural Artibonite Valley is surprisingly close to the STD prevalence rate found in pregnant women in Cite Soleil, an urban slum of Port au Prince. ${ }^{19}$ The prevalence rate of cervical infection was $12 \%$ in both areas; the prevalence rate of syphilis was $7 \%$ in rural Haiti versus $11 \%$ in urban Haiti. In rural Haiti, $40 \%$ of women had at least one STD compared with $47 \%$ in urban Haiti. In most developing countries, the prevalence rate of STDs is substantially higher in urban areas than in rural areas and consequently STD prevention and treatment resources are targeted at urban areas. ${ }^{1,2}$ In Haiti, with $70 \%$ of the population living in rural areas, ${ }^{20}$ and with the high STD rates

TABLE 2

Prevalence rates and median age of women with sexually transmitted diseases (STD) among 476 women attending antenatal-care clinics in Haiti's Artibonite Valley

\begin{tabular}{|c|c|c|c|c|c|}
\hline \multirow[b]{2}{*}{ Disease } & \multicolumn{2}{|c|}{ Prevalence } & \multicolumn{3}{|c|}{ Median age (years) } \\
\hline & Number & $\%$ & Infected & Uninfected & $P$ value \\
\hline Trichomonas & $121 / 476$ & 25.4 & 24 & 26 & 0.040 \\
\hline Gonorrhea & $11 / 475$ & 2.3 & 19 & 26 & 0.020 \\
\hline Chlamydia & $51 / 475$ & 10.7 & 22 & 26 & $<0.001$ \\
\hline Syphilis & $32 / 474$ & 6.8 & 30.5 & 25 & 0.009 \\
\hline HIV & $20 / 469$ & 4.3 & 27 & 25 & NS \\
\hline At least one STD & $191 / 476$ & 40.1 & - & - & - \\
\hline
\end{tabular}

HIV = human immunodeficiency virus; NS = not significant. 
TABLE 3

Risk factors and risk markers for cervical infection with Neisseria gonorrhoeae and/or Chlamydia trachomatis by multivariate analysis

\begin{tabular}{lcc}
\hline \multicolumn{1}{c}{ Risk } & Odds ratio* & $\begin{array}{c}95 \% \\
\text { confidence interval }\end{array}$ \\
\hline Age less than 21 years & 2.8 & $1.4-5.5$ \\
Child's father is a truck driver & 4.3 & $1.5-12.5$ \\
Separated from child's father & 2.9 & $1.2-7.0$ \\
Positive urine leukocyte & 3.5 & 0.003 \\
$\quad$ esterase dipstick & $1.8-6.8$ \\
\hline * Odds ratios were adjusted for other variables in the table and living with the child's father. & 0.007 \\
\hline
\end{tabular}

reported in this study, we strongly recommend a more equitable distribution of resources between urban and rural areas.

Social and anthropologic studies suggest that deepening poverty in rural Haiti may be leading to new patterns of sexual unions. ${ }^{8-11}$ Data from this report suggest that these new patterns may be associated with STD transmission. Studies suggest that women in rural Haiti are entering sexual unions at a younger age. ${ }^{21-23}$ In 1972 the average age of first sexual union for women in the Artibonite Valley was 21 years, and in 1996 the age was 19. In the current study, an age less than 21 was the strongest risk factor for cervical infection with Neisseria gonorrhoeae and/or Chlamydia trachomatis. The median age of women with gonorrhea was only 19 years. Given the association between young age and cervical infection, one can postulate that the trend toward earlier sexual activity may be associated with increased transmission of gonorrhea and chlamydia.

Several studies from rural Haiti describe an increasing number of women who enter into a series of sexual relationships out of economic necessity. ${ }^{10,11,24,25}$ Because of the lack of economic possibilities for women in rural Haiti, single women with children must rely upon men for economic support. Single mothers search for a male partner to provide food and housing for themselves and their children; these women enter into a plasaj sexual relationship with the new partner and have more children with him. While the women may be monogamous, the man is often plase with several women. This relationship often dissolves within a few years, and the woman is left with additional children and the need to find a new partner.

Our study suggests that this pattern of serial plasaj is common in rural Haiti. Nearly one-third of the women in this study reported entering a sexual relationship out of economic necessity and of these, $95 \%$ had children by multiple fathers, a pattern strongly associated with syphilis and HIV infection.
Women in plasaj had increased odds of having syphilis (OR 3.0) and HIV infection (OR 8.3). Women who entered a sexual relationship out of economic necessity also had increased odds of having syphilis (OR 2.3) and HIV infection (OR 6.3). We postulate that social and economic instability in rural Haiti may be pushing an increasing number of women into serial plasaj and thereby fueling the syphilis and HIV epidemics.

As a cross-sectional prevalence study, this research was not able to fully capture the dynamic nature of the HIV epidemic in rural Haiti. Longitudinal studies with incidence data will be needed to further define the relationship between economic hardship and the HIV epidemic.

To prevent the morbidity and mortality associated with STDs, ${ }^{26}$ rural Haiti needs primary STD prevention. One costeffective prevention strategy is to target groups of individuals within the population who are at high risk for disease transmission. ${ }^{27}$ The data in this report suggest two high-risk groups: adolescents and women in serial plasaj. Programs in other countries that encourage adolescents to delay the onset of sexual activity and to use condoms when sexually active have been successful. ${ }^{28}$ These programs could serve as a model for such an intervention in rural Haiti. Additional strategies are needed for primary prevention of HIV. Programs stressing behavior modification may have little impact on a desperate mother seeking to insure the survival of her children through a series of sexual relationships. Because continued childbearing appears to be an essential aspect of these relationships, promotion of condom use may be of little benefit. Education and family planning programs for young women may help them avoid unwanted pregnancies and a life of serial plasaj. Development programs that help single mothers become economically self-sufficient may also prevent serial plasaj and thereby be an effective means of preventing HIV transmission in rural Haiti.

Strategies are also needed for the management of people

TABLE 4

Risk factors for positive syphilis serology by multivariate analysis

\begin{tabular}{|c|c|c|c|}
\hline Risk & Odds ratio $\dagger$ & $\begin{array}{c}95 \% \\
\text { confidence } \\
\text { intervals }\end{array}$ & $\begin{array}{c}P \\
\text { value }\end{array}$ \\
\hline In plasaj* $^{*}$ with father & 3.0 & $1.2-7.8$ & 0.025 \\
\hline $\begin{array}{l}\text { Reports entering a sexual relationship } \\
\text { out of economic necessity }\end{array}$ & 2.3 & $1.0-5.2$ & 0.039 \\
\hline $\begin{array}{l}\text { Reports spontaneous abortion during } \\
\text { previous pregnancy }\end{array}$ & 2.3 & $1.2-4.7$ & 0.016 \\
\hline Reports the death of a previous child & 2.5 & $1.6-3.9$ & $<0.001$ \\
\hline Infection with gonorrhea & 6.7 & $1.2-35.8$ & 0.028 \\
\hline
\end{tabular}

* Plasaj is a long-term sexul relationship, commonly not monogamous and not formalized by religious or civil ceren

$\dagger$ Odds ratios were adjusted for other variables in the table. 
TABLE 5

Risk factors for HIV infection by multivariate analysis

\begin{tabular}{|c|c|c|c|}
\hline Risk & Odds ratio $\dagger$ & $\begin{array}{c}95 \% \\
\text { confidence } \\
\text { intervals }\end{array}$ & $\begin{array}{c}P \\
\text { value }\end{array}$ \\
\hline In Plasaj* with father & 8.3 & $1.8-39.4$ & 0.007 \\
\hline Reports entering a sexual relationship & 63 & $20-107$ & רח0 \\
\hline Father of child is a merchant & 8.7 & $2.3-33.7$ & 0.002 \\
\hline Number of pregnancies & 0.73 & $0.54-0.98$ & 0.038 \\
\hline Reports vaginal pruritis & 3.1 & $1.2-8.5$ & 0.038 \\
\hline
\end{tabular}

* Plasaj is a long-term sexual relationship, commonly not monogamous and not formalized by religious or civil ceremony.
$\dagger$ Odds ratios were adjusted for other variables in table.

already infected with STDs. Symptomatic STDs can be managed effectively using syndromic algorithms and empiric antibiotics. ${ }^{29}$ However, since a large percentage of STDs are asymptomatic, detection requires a screening test. This is particularly problematic for pregnant women, as vertical transmission from asymptomatic mothers to their offspring is a cause of significant morbidity and mortality. ${ }^{30-35}$

Screening pregnant women in rural Haiti for gonorrhea and chlamydia is difficult. In this study, symptoms elicited during medical history were not predictive of cervical infection. Current laboratory tests for gonorrhea and chlamydia are expensive and not routinely done in Haiti. A number of clinical algorithms have been developed for the diagnosis of gonorrhea and chlamydia that rely upon historical risk factors and clinical exam. ${ }^{36-38}$ However, most of these algorithms are too insensitive or too cumbersome for application in the field. This study and others have shown that the urine LED is too insensitive and non-specific for use as an independent screening tool for cervical infection. ${ }^{39,40}$ A technically simple and inexpensive diagnostic test appropriate for use in developing countries is needed for the detection of asymptomatic cervical infections. Unfortunately, no such test exists.

For syphilis, simple screening and treatment strategies are available. In prenatal clinics where RPRs can be performed on-site, syphilis can be diagnosed and treatment can be started on the same day, ${ }^{41}$ a strategy that has been implemented at Hospital Albert Schweitzer. Despite the existence of this simple, affordable screening strategy, many women in rural Haiti do not have access to it, and syphilis remains a leading cause of perinatal death, ${ }^{4,30}$ a situation that should not be tolerated. Every pregnant woman in Haiti should have access to syphilis screening with same-day treatment.

Acknowledgments: The authors wish to thank Gretchen and Warren Berggren and Enide Monfleury.

Financial support: This study was completed through the assistance of the United States Agency for International Development (USAID) under the terms of contracts 521.0248C00600600 (MSH) and 6230238-A-00-4031-00 (AIDSCAP), and a grant from the United States Public Health Service TW00002.

Disclaimer: The views and opinions contained in this report are the authors' own and are not intended as statements of the policy of USAID.

Authors' addresses: Daniel W. Fitzgerald and Jennifer Fitzgerald, clo Lynx Air P.O. Box 407139, Fort Lauderdale, FL 33340. Frieda Behets, 75 Cottage St., New Haven, CT, 06511. Angie Caliendo, Infectious Disease Unit, Massachusetts General Hospital, Boston, MA, 02124. Dominique Roberfroid, Catherine Lucet, and Luc Kuy- kens, $\%$ Hospital Albert Schweitzer, 10 Rue Clercine, Zone Tabarre, Port au Prince, Haiti.

\section{REFERENCES}

1. Piot P, Tezzo R, 1990. The epidemiology of HIV and other sexually transmitted infections in the developing world. Scand J Infect Dis 69 (suppl): 89-97.

2. Over M, Piot P, 1993. Sexually transmitted diseases. Jamison DT, Mosley WH, Mearsham AR, Bobadilla JL, eds. Disease Control Priorities in Developing Countries. New York, NY: Oxford University Press, 455-528.

3. Pape J, Johnson WD, 1993. AIDS in Haiti:1982-1992. Clin Infect Dis 17 (Suppl 2): S341-S345.

4. Fitzgerald DW, Behets F, Lucet C, Roberfroid D, 1998. The prevalence, burden, and control of syphilis in Haiti's rural Artibonite region. Int $J$ Infect Dis 2: 127-131.

5. The World Bank, 1998, Haiti, les defis de la lutte contre la pauvrete rapport no. 17242-HA. Washington, DC: The World Bank, 1-8.

6. Centers for Disease Control, 1990. MMWR 40: 222-225.

7. Cayemittes M, Rival A, Lerebours G, Barrere B, 1994/95. Survey on Mortality, Morbidity and Utilization of Services (EMMUS-II). Port au Prince, Haiti: Centre Des Enfants Haitiennes/USAID, 15

8. Harvard Center for Population and Development, 1993. Crisis in humanitarian action, crisis in Haiti. Program on human security working paper series. Cambridge, MA: Harvard University School of Public Health, 1-10.

9. Gibbons E, Garfield R 1999. The impact of economic sanctions on health and human rights in Haiti, 1991-1994. Am J Public Health 89: 1499-1504.

10. Farmer P, 1992. AIDS and Accusation, Haiti and the Geography of Blame. Berkley, CA: University of California Press, 121151.

11. Farmer P, 1995. Culture, poverty, and HIV transmission: the case of rural Haiti. Brummelhuis H, Herdt G, eds. Culture and Sexual Risk: Anthropological Perspectives on AIDS. New York, NY: Gordon and Breach, 3-28.

12. Berggren WL, Ewbank DC, Berggren GG, 1981. Reduction of mortality in rural Haiti through a primary-health-care program. N Engl J Med 304: 1324-1330.

13. Division du recensement et des enquetes nationals, 1990. Recensement general de la population et du logement: resultat pour le department de l'Artibonite. Port au Prince, Haiti: Institut Haitien de Statistique et d"Informatique.

14. Ministere de la Sante Publique et de la Population, 1996. Plan national strategique pour la prevention et le controle du SIDA et des MST. Port au Prince, Haiti: Haitian Ministry of Public Health and Population, 18-19.

15. Ministere de la Sante Publique et de la Population, 1996. La prise en charge des maladies sexuellement transmissibles en Haiti: protocoles pour les soins de sante primaire 1996. Port au Prince, Haiti: Haitian Ministry of Public Health and Population.

16. Kagadye R, Klokke A, Nicoll A, 1993. Sentinel surveillance for HIV-1 among pregnant women in a developing country: 3 
years experience and comparison with a population serosurvey. AIDS 7: 849-855.

17. Borgdoff M, Barrongo L, Jaarsveld E, 1993. Sentinel surveillance for HIV-1 infection: how representative are blood donors, outpatients with fever, anemia, or sexually transmitted diseases and antenatal clinic attenders in Mwanza, Tanzania. AIDS 7: 567-572.

18. Chin, J, 1990. Public health surveillance of AIDS and HIV infections. Bull World Health Organ 68: 529-536.

19. Behets F, Desormeaux J, Joseph D, 1995. Control of sexually transmitted diseases in Haiti: results and implications of a baseline study among pregnant women living in Cite' Soleil shantytowns. J Infect Dis 172: 764-761.

20. United Nations 1995. Statistical Yearbook, Issue 40. New York: UN Publications, 47.

21. Berggren G, Murthy N, Williams S, 1972. Rural Haitian women: an analysis of fertility rates. Soc Biol 21: 368-378.

22. Allman J, 1982. Fertility and family planning in Haiti. Stud Fam Plann 13: 237-245.

23. Hospital Albert Schweitzer 1996. Reproductive Health Survey of the Artibonite Valley, 1996. Port au Prince, Haiti: Management Sciences for Health, 1-20.

24. Maynard-Tucker G, 1996. Haiti: unions, fertility, and the quest for survival. Soc Sci Med 43: 1379-1387.

25. Devin RB, Erickson P, 1996. The influence of male caregivers on child health in rural Haiti. Soc Sci Med 43: 479-488.

26. De Schryver A, Meheus A, 1990. Epidemiology of sexually transmitted diseases: the global picture. Bull World Health Organ 68: 639-654.

27. Over M, Piot P, 1996. Human immunodeficiency virus infection and other sexually transmitted diseases in developing countries: public health importance and priorities for resource allocation. J Infect Dis 174 (suppl 2): S162-S175.

28. Kim N, Stanton B, Li X, Dickerson K, Galbraith J, 1997. Effectiveness of the 40 adolescent AIDS risk reduction interventions. J Adolesc Health 20: 204-215.

29. World Health Organization (WHO) 1994. Global Programme on AIDS and Sexually Transmitted Diseases. (WHO/GPA/ TEM/94.1). Geneva, Switzerland: WHO.

30. McDermott J, Steketee R, Larsen S, Wirima J, 1993. Syphilis associated perinatal and infant mortality in rural Malawi. Bull World Health Organ 71: 773-780.

31. Martin DH, Koutsky L, Eschenbach DA, Daling JR, Alexander
ER, Benedetti JK, Holmes KK, 1982. Prematurity and perinatal mortality in pregnancies complicated by maternal Chlamydia trachomatis infections. JAMA 247: 1585-1588.

32. Preece PM, Anderson JM, Thompson RG, 1989. Chlamydia trachomatis infection in infants: a prospective study. Arch Dis Child 64: 525-529.

33. Fransen L, Volker K, 1988. Neonatal ophthalmia in the developing world. International Opthalmology 11: 189-196.

34. Schachter J, Holt J, Goodner E, Grossman M, Sweet R, Mills J, 1979. Prospective study of chlamydial infection in neonates. Lancet 8139: 378-379.

35. Donders GGG, Moerman P, De Wet GH, Hooft P, Goubau P 1991. The association between Chlamydia cervicitis, chorioamnionitis, and neonatal complications. Arch Gynecol Obstet 249: 79-85.

36. Braddick MR, O Ndinya-Achola J, Mirza NB, Plummer FA Irungu G, Sinei SK, Piot P, 1990. Towards developing a diagnostic algorithm for Chlamydia trachomatis and Neisseria gonorrhoeae cervicitis in pregnancy. Geniturin Med 66: 6265.

37. Vuylsteke B, Laga M, Alary M, Gerniers M, Lebughe J, Nzila N, Behets F, Van Dyck E, Piot P, 1993. Clinical algorithms for screening of women for gonococcal and chlamydial infection: evaluation of pregnant women and prostitutes in Zaire. Clin Infect Dis 17: 82-88.

38. Behets FM-T, Williams Y, Brathwaite A, 1995 Management of vaginal discharge in women treated at a Jamaican sexually transmitted diseases clinic: use of diagnostic algorithms versus laboratory testing. Clin Infect Dis 21: 1450-1455.

39. Tyndall MW, Kidula N, Sande J, Ombette J, Temmerman M, 1999. Predicting Neisseria gonorrheae and Chlamydia trachomatis infection using risk scores, physical examination, microscopy, and leukocyte esterase dipstick among asymptomatic women attending a family planning clinic in Kenya. Sex Transm Dis 26: 476-482.

40. Chow JM, Moncada J, Brooks D, Bolan G, Shaw H, Shachter J, 1996. Is urine leukocyte esterase test a useful screening method to predict Chlamydia trachomatis infection in women? J Clin Microbiol 34: 534-536.

41. Jenniskens F, Obwaka E, Kirisuah S, Moses S, Yusufali FM, Achola JO, Fransen L, Laga M, Temmerman M, 1995. Syphilis control in pregnancy: decentralization of screening facilities to primary care level, a demonstration project in Nairobi, Kenya. Int J Gyn Obstet 48 Suppl: S121-S128. 